\title{
Primary Hydatid Cyst and Isolated from the Thigh: An Exceptional Localization
}

\author{
Daoudi $\mathbf{M}^{1^{*}}$, El Mezouari $\mathbf{E}^{2}$, Azriouil $\mathbf{O}^{1}$, Boukhris $\mathbf{J}^{1}$, Margad $\mathbf{O}^{1}$, Nadir $\mathbf{Y}^{1}$, El Fikri $\mathbf{A}^{3}$, Moutaj $\mathbf{R}^{2}$, Koulali \\ $\mathrm{KI}^{1}$ \\ ${ }^{1}$ Department of Traumatology-Orthopedics, Avicenna Military Hospital, Marrakech, Morocco \\ ${ }^{2}$ Service de Parasitology-Mycology, Avicenna Military Hospital, Marrakech, Morocco \\ ${ }^{3}$ Department médical Radiology, Hospital Militaire Avicenna Militaty Hospital, Marrakech, Morocco
}

"Corresponding Author: Dr. Daoudi Mohamed, Department of Traumatology-Orthopedics, Avicenna Military Hospital, Marrakech, Morocco, E-mail: daoudimonsa@gmail.com

Received: 22 October 2018; Accepted: 01 November 2018; Published: 13 November 2018

\begin{abstract}
Muscular involvement with Echinococcusgranulosus is rare, even in endemic countries where the frequency is estimated to be less than 3\%, particularly in the countries of the Mediterranean basin, North Africa and Latin America. We report the rare observation of a hydatid cyst of the internal thigh room in a 57-year-old patient of rural origin and who has no notable sickness antecedents and was hospitalized in our department for the exploration of a tumefaction of the internal surface of the left thigh appeared gradually and insidiously for 3 years. Magnetic resonance imaging (MRI) showed an oval mass evoking an intramuscular hydatid cyst and its relationship to neighboring structures. He underwent surgical excision under locoregional anesthesia. Solitary hydatid localization in muscle tissue is exceptional, but it is useful to know that its diagnosis is often delayed, its treatment is surgical, but recurrences are possible.
\end{abstract}

Keywords: Hydatid disease; Cyst; Muscle; Anesthesia; Surgical

\section{Introduction}

Muscular involvement with Echinococcusgranulosus is rare, even in endemic countries where it is estimated to be less than 3\%, particularly in the countries of the Mediterranean basin, North Africa and Latin America [1]. The 
primary and isolated muscular localization of a hydatid cyst $(\mathrm{KH})$ is exceptional [2]. Most cysts (60\%) develop in the liver; The other development sites are the lung (20\%) and less frequently the spleen, heart, kidney, central nervous system, and the bone [3]. We report the rare observation of a hydatid cyst isolated from the inner thigh loge in a 57 years old subject living in the rural environment and we discuss the epidemiological aspects, the diagnostic difficulties and the therapeutic modalities of this pathology.

\section{Case Observation}

A 57-year-old rural patient with no notable antecedents had been hospitalized in our department to investigate a tumefaction of the internal face of the left thigh that had appeared progressively and insidiously for 3 years. This lesion, initially asymptomatic, caused, 4 months ago, unsystematized pains of the lower left limb. During examination he was apyretic and in good general condition. The palpation of the internal surface of the left thigh found a voluminous mass, poorly limited, adherent to the deep plan, slightly sensitive to a skin in normal view and without signs of nervous or vascular compression. Standard radiographs had shown soft tissue thickening without calcifications and without bone abnormalities. The chest X-ray was normal. The MRI of the thigh showed a multilobular oval mass measuring $25 \mathrm{~cm}$ in length by $8 \mathrm{~cm}$ in width, containing partitions with small rounded images of fluidic signal evoking an intramuscular hydatid cyst (Figure 1). The biological record showed hypereosinophilia at 5,1\%, with negative hydatid serology. The thoraco-abdomino-pelvic CT did not reveal any other sites. He had undergone surgical excision under locoregional anesthesia (Figure 2). Preoperatively, the cleavage plan was not evident, and adjoined to the superficial femoral artery in spite of which a perkystectomy was performed (Figure 3) carrying the whole tumor. The opening of the surgical specimen found multiple daughter vesicles (Figure 4). The parasitological study showed numerous protoscolexes of Echinococcus granulosus (Figure 5). The operative sequences were simple. A medical treatment was followed for 6 months, after a one-year followup, clinical, serological and ultrasound monitoring did not demonstrate recurrence.

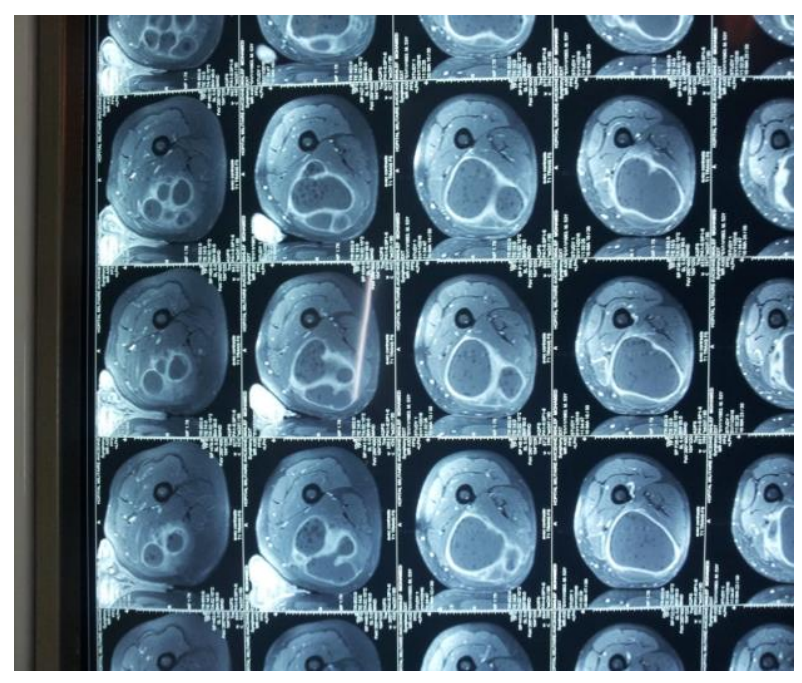

Figure 1: Aspect in magnetic resonance imaging (MRI) of an intramuscular hydatid cyst (KH). 


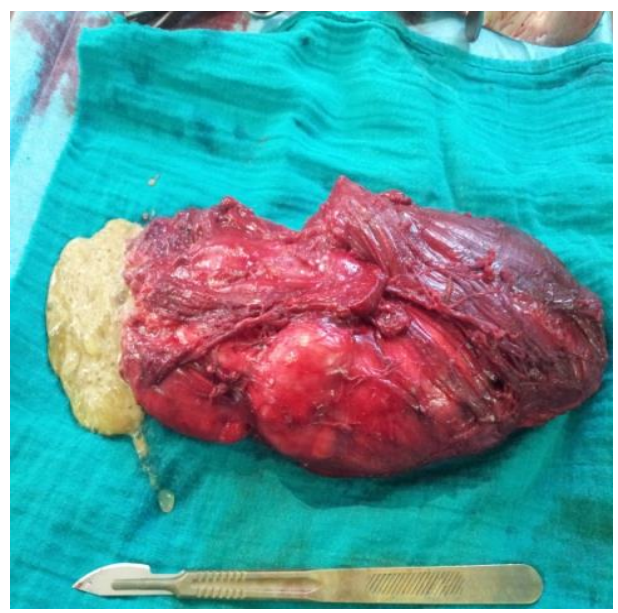

Figure 2: Piece of resection.

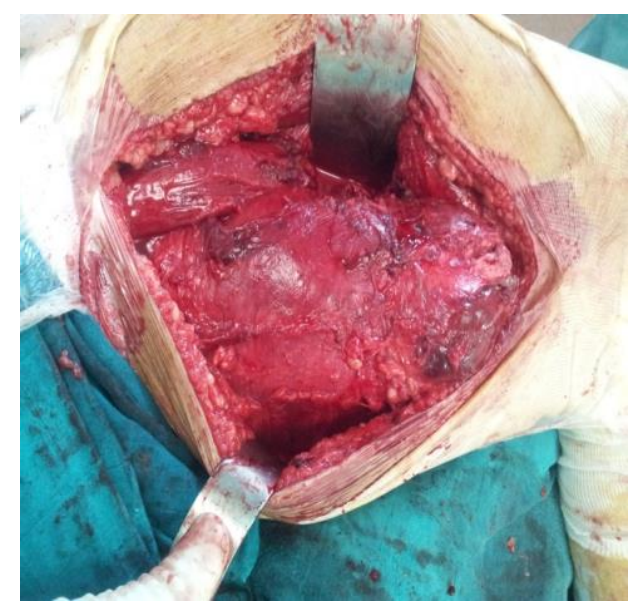

Figure 3 : Perikystectomy of the tumor.

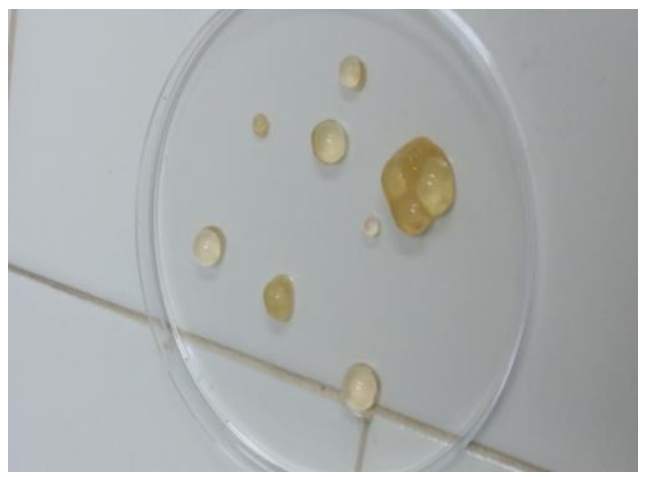

Figure 4: Opening of the surgical specimen and recovery of female vesicles. 


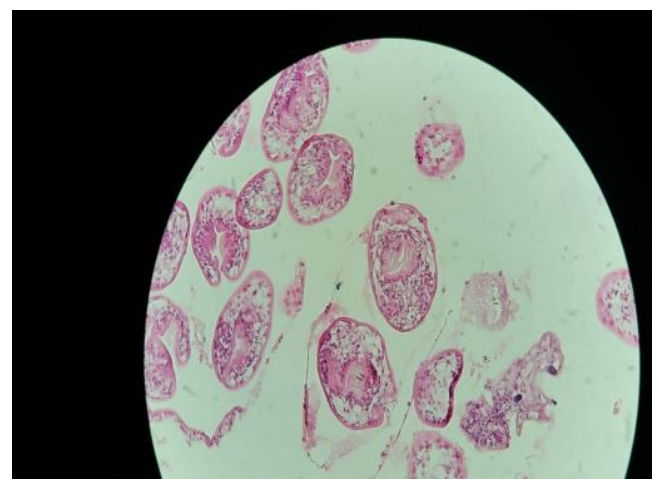

Figure 5: Protoscolex at high magnification.

\section{Discussion}

Hydatidosis is an endemic disease that poses a public health problem in certain areas in the world where livestock and sheep are farmed, particularly in the Mediterranean, the Middle East and South America [4]. This parasitosis is caused by the larva of TaeniaEchinococcusgranulosus which lives in the digestive tubetract of dogs, domestic or wild, and other carnivorous animals of which they are the definitive hosts. Humans are the accidental intermediate hosts when they ingest Taenia eggs [5]. Liver (60\% of cases) and lung (20\% of cases) are the two most frequent sites. This can be explained by the physiological role of the organs. Thus they constitute a double physiological filter in the dissemination of the parasite, making the extra-hepato-pulmonary localizations less frequent [6]. The incubation period can last from 5 to 20 years and symptoms occur several years after exposure [7]. The primary muscular hydatid cyst is rare even in endemic areas. Its frequency varies from 1 to 5\%. Hexacanth embryos that penetrate by digestive tract are most often stopped by the filters that constitute the liver and the lungs [3]. Primary muscle damage is described in the literature for chest wall musculature, pectoral major, sartorius, quadriceps and gluteus [6-8].

In the case presented, the muscular localization was located with respect to the internal room of the thigh. MRI is the examination selected in hydatic pathology of the soft parts [5]. It allows, thanks to its high resolution in contrast, to better study the locoregional extension of the lesion and its relations with the vasculonerveous pedicles, while offering a careful analysis of the cystic walls. Ultrasound-guided needle biopsies are also an aid in diagnosis, although some authors do not recommend them because of the risk of cystic rupture and anaphylactic reaction [9]. The results of microscopic analyzes of needle biopsy are not guaranteed, especially if the patients have received medical treatment, and the biopsy area must be resected within the time of surgery [4]. Various serological tests may assist the diagnosis of echinococcosis. However, serology alone is not sufficient for diagnosis. There are 50\% negative mistakes in patients with lung cysts [10]. The sensitivity and specificity of serological tests are not known in patients with soft tissue echinococcosis. This serology may be useful for monitoring the treatment when it is positive [4]. The treatment of muscular echinococcosis is surgical [4]. Surgery should be careful, avoiding the opening of the cyst during dissection. The surgical site must be protected by a solution of hypertonic saline and/or 
oxygenated water from the surgical approach [11]. The technique to be selected is the perkystectomy, taking the whole cyst without breaking the wall. The monoblock excision with complete pericystectomy is the ideal procedure, but not always feasible especially if the cyst is large and deep, contacting neighboring vasculo-nervous elements [11]. The interest of medical treatment with benzimidazole derivatives (albendazole) in the solitary locomotor system remains controversial because of the poor diffusion in the cystic fluid $[4,12]$. This treatment is reserved for inoperable cases or in addition to surgery when the cyst is complicated with rupture [13].

\section{Conclusion}

Solitary hydatid localization in muscle tissue is exceptional, but it is useful to know it. The clinical picture is often poor and can mimic a soft tissue tumor. The diagnosis is confirmed by MRI. The treatment is surgical.

\section{Conflict of Interest}

No conflicts of interest.

\section{References}

1. Kazakos CJ, Galanis VG, Verettas DA, et al. Primary hydatid disease in femoral muscles. J Int Med Res 33 (2005): 703-706.

2. Cissé AM, Nassar I, Hammani L, et al. Hydatidose primitiv et étendue de la cuisse : aspect radiologique inhabituel.J Radiol 83 (2002): 1778-1780.

3. Jerbi Omezzine S, et al. Kyste hydatique primitif de la cuisse. Une localisation rare. Revue de chirurgie orthopédique et traumatologique 96 (2010): 105-108.

4. Amar MF, et al. Journal de Traumatologie du Sport 27 (2010): 146-148.

5. Rafiqi K, Rafaoui A, Sirrajelhak M, et al. Kyste hydatique primitif de la cuisse chez un bodybuilder. À propos d'un cas et revue de la littérature. Journal de Traumatologie du Sport 33 (2016): 107-109.

6. Dawson JL, Stamatakis JD, Stringer MD, et al. Surgical treatment of hepatic hydatid disease. Br J Surg 75 (1988): 946-950.

7. Ozkoc G, Akpinar S, Hersekli MA, et al. Primaryhydatiddisease of the quadriceps muscle: a rare localization. Arch Orthop Trauma Surg 123 (2003): 314-316.

8. Combalia A, Sastre S. Kyste hydatique du muscle glutéal. Deux cas. Revuede la littérature. Rev Rhum 72 (2005): 851-857.

9. Ozkoc G, Akpinar S, HersekliMA, et al. Primary hydatid disease of the quadriceps muscle: a rare localization. Arch Orthop Trauma Surg 123 (2003): 314-316.

10. Kammerer WS, Schantz PM. Echinococcal disease. Infect Dis Clin North Am 7 (1993): 605-618.

11. Mseddi M, Mtaoumi M, Dahmene J, et al. Ben AyecheHydatid cysts in muscles: eleven cases. Revue de chirurgie orthopédique 91 (2005) 267-271. 
12. Hammami $\mathrm{T}$, Noomane $\mathrm{F}$, Ketata $\mathrm{M}$, et al. Kyste hydatique musculaire de la cuisse. À propos de trois observations.Rev Chir Orthop Reparatrice Appar Mot 88 (2002): 193-196.

13. Daoudi A, Loudiyi WD, Elibrahimi A, et al. Le kyste hydatique sous-cutané solitaire de la région glutéale: une localisation inhabituelle. À propos d'un cas. Ann Chir Plast Esthet 53 (2008): 448-451.

Citation: Daoudi M, El Mezouari E, Azriouil O, Boukhris J, Margad O, Nadir Y, El Fikri A, Moutaj R, Koulali KI. Primary Hydatid Cyst and Isolated from the Thigh: An Exceptional Localization. Archives of Clinical and Medical Case Reports 2 (2018): 221-226.

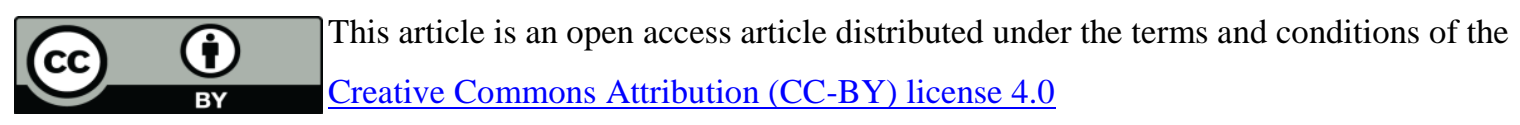

